\title{
Flexural strength of silica fume, fly ash, and metakaolin of hardened cement paste after exposure to elevated temperatures
}

\author{
Nabil Abdelmelek ${ }^{1} \cdot$ Eva Lubloy $^{1}$ (D) \\ Received: 23 August 2020 / Accepted: 10 August 2021 / Published online: 13 September 2021 \\ (c) The Author(s) 2021
}

\begin{abstract}
The mechanical properties of concrete based mainly on flexural and compressive bearing capacity. Generally, researchers have an interest in the evaluation of compression property through the importance of the flexural performance of the material in the constructions, namely the significance of each mechanical property based upon the position of the structural element. The present experimentally work is directed toward improving the flexural strengths performance of ordinary hardened cement paste (HCP) at ambient and after elevated temperatures exposure. The used parameters were different pozzolanic materials with different replacements ratios to cement mass and different levels of temperature. Results proved the significant contribution of pozzolanic material to enhance the flexural properties of HCP after being exposed to elevated temperatures. The low content of $\mathrm{CaO}$, the high grinding fineness, and the physical morphology of the used pozzolanic materials, made their adoption effective to HCP after exposure to elevated temperatures. Using 3\%,12\%, and 15\% of silica fume (SF), metakaolin (MK), and fly ash (FA), respectively, showed the highest heat endurance among the other replacements. However, the optimum replacement of MK has shown a better heat endurance than the optimum replacements of SF and FA. On the other hand, the spalling has occurred at high replacements of SF. Finally, the results are supported by means of thermo-gravimetric, SEM, and computed tomography investigations.
\end{abstract}

Keywords Silica fume $\cdot$ Fly ash $\cdot$ Metakaolin $\cdot$ Elevated temperatures $\cdot$ Hardened cement paste $\cdot$ Supplementary cementitious materials $\cdot$ Computed tomography

\section{Introduction}

Concrete is a composite material composed mainly of aggregate and hardened cement paste (HCP) were bounded together as complex material. The cement paste is a porous material, normally possesses large free water content. In addition to that, the HCP consists of sheets of calcium silicate hydrate $(\mathrm{CSH})$, crystals of $\mathrm{Ca}(\mathrm{OH})_{2}$, and anhydrous cement particles. Concrete can expose to elevated temperatures everywhere due to fire accidents, during this situation concrete undergoes a consecutive series of chemical and physical changes. In fact, these changes during elevated

Eva Lubloy

lubloy.eva@epito.bme.hu

Nabil Abdelmelek

abdelmelek.nabil@epito.bme.hu

1 Department of Construction Materials and Technologies, Faculty of Civil Engineering, Budapest University of Technology and Economics, Budapest 1521, Hungary temperature primarily occur in the $\mathrm{HCP}$, but to some extent occur in the aggregate [1,2]. Since the bonding capacity of concrete relates strongly to the hardened paste, therefore any deterioration of the HCP causes a decline in the mechanical and durability properties of concrete [3-6].

Several researchers have reported that the changes in the volume of HCP after exposure to elevated temperatures is one of the major problems results. Initially, the HCP exhibits expansion after heating up to $150{ }^{\circ} \mathrm{C}$, the evaluation of maximum expansion results is to about $0.2 \%$ to the total volume. Then no further expansion occurs up to $300{ }^{\circ} \mathrm{C}$. Further increase of temperatures up to $800{ }^{\circ} \mathrm{C}$, the $\mathrm{HCP}$ showed shrinkage of volume to reach $2.2 \%[1,7]$. The abovementioned results were mainly caused by the decomposition of $\mathrm{Ca}(\mathrm{OH})_{2}, \mathrm{CaCO}_{3}$, and $\mathrm{CSH}$ gel [8].

From another hand, many studies concluded that HCP contains supplementary cementitious materials (SCM) such as silica fume (SF), fly ash (FA), and slag showed better compressive strength than ordinary Portland HCP when exposed to elevated temperature [9]. Meanwhile, 
Field surveys have present that the fire collapse to concrete includes the loss in the mechanical strength property, cracking, and sometimes explosive spalling [10,11]. It has been proved that the critical range of temperature exposure for the mechanical strength loss is between 400 and $800{ }^{\circ} \mathrm{C}$ [12]. Hertz [13] investigated concrete containing $14-20 \%$ of SF replacements to cement mass, results indicated that concrete containing SF is highly prone to spalling and cracking at elevated temperatures. Sarshar and Khoury [14] investigated HCP containing $0 \%$ and $30 \%$ pulverized FA under a series of different temperatures levels up to $650{ }^{\circ} \mathrm{C}$. Results showed that the relative residual compressive strength was $88 \%$ and $73 \%$ at $450{ }^{\circ} \mathrm{C}$ and $600{ }^{\circ} \mathrm{C}$, respectively, which was almost double than the residual pure ordinary Portland cement (OPC) pastes strength. Poon et al. [15] studied high-strength concrete (HSC) containing MK up to $20 \%$ after exposure to temperatures. It was evaluated that the MK concrete suffered a more severe loss of compressive strength and permeability-related durability than FA, SF, and OPC concrete after exposure to elevated temperatures. In addition, explosive spalling was observed in both normal and high strength MK concretes, noting that the frequency increases as MK contents increases.

HCP is characterized by low flexural strengths, which are typically between 3 and $10 \mathrm{MPa}$. Usually, studies of HCP properties are corresponding to the compressive strength properties. Few numbers of studies which have focused on the flexure property of $\mathrm{HCP}$, concluding that the major weakness of HCP is due to the presence of pores [16]. Additionally, pozzolanic materials are an appropriate material and play an important role in the properties of HCP contributing to the physical filling of the pores and pozzolanic action [17].

Finally, limited studies on the mechanical properties of HCP after exposure to elevated temperatures, particularly there is a lack of information about flexural behavior in the literature. Knowing that the behavior of compression property is not similar to flexural property especially at elevated temperatures, the flexural property is very sensitive to cracks more than compression one. Generalizing conclusions from compressive tests is to some extent not accurate particularly in case of using fine SCM. Besides, providing a heat endurance $\mathrm{HCP}$ after exposure to elevated temperatures containing SCM is the objective of this study. Furthermore, defining the optimum replacements of SF, MK, and FA after exposure to elevated temperature by using short incremental replacement is also one of the objectives. Reaching more information about the microstructure of the HCP blended by SCM before and after exposure to elevated temperatures has been carried by some modern techniques i.e., Thermo-Gravimetric (TG), Scanning Electro-Microscopic (SEM), and Computed Tomography (CT).

\section{Experimental work}

\section{Materials}

The materials used in this experimental program were OPC, SF, MK, and FA, they are provided by a Hungarian company (Duna Drava, Newchem, and Sika companies). Where the physical and chemical properties of the cement and the pozzolanic materials are presented in Table 1, which these properties were tested following the European standards [MSZ EN 196-2: (2013) and MSZ EN 525-12: (2014)] [18, 19]. The cement used to conduct the present study was an OPC (CEM I $42.5 \mathrm{~N}$ ) in accordance with EN 197-1:2000 [20]. The CEM I $42.5 \mathrm{~N}$ constitutes mainly $\mathrm{CaO}$. The crystalline phases could be defined as $\mathrm{Ca}_{3} \mathrm{SiO}_{5}\left(\mathrm{C}_{3} \mathrm{~S}\right.$, alite, hatrurite) as main crystalline component; $\mathrm{Ca}_{2} \mathrm{SiO}_{4}\left(\mathrm{C}_{2} \mathrm{~S}\right.$, belite, larnite) presence cannot be excluded; $\mathrm{CaSO}_{4} \cdot 2 \mathrm{H}_{2} \mathrm{O}\left(\mathrm{CSH}_{2}\right.$, gypsum); $\mathrm{Ca}_{4} \mathrm{Al}_{2} \mathrm{Fe}_{2} \mathrm{O}_{10}\left(\mathrm{C}_{4} \mathrm{AF}\right.$, brownmillerite). The abbreviations within Fig. 1 are A: Alite $\left(\mathrm{C}_{3} \mathrm{~S}\right)$; B: Belite $\left(\mathrm{C}_{2} \mathrm{~S}\right)$; C: Brownmillerite (C4AF); and D: Gypsum $\left(\mathrm{CSH}_{2}\right)$. On the other hand, pozzolanic materials are mostly amorphous. Figure 2 shows the particle size distribution curves for cement and the three SCM. The used water in the current study is tap water, which complies with the standard requirements of EN 1008:2002 [21].

\section{Mixing procedures}

Mixing was carried out in the temperature room of $20 \pm 2{ }^{\circ} \mathrm{C}$ in different stages: (i) dry mixing for binder (cement and type of SCM) within $30 \mathrm{~s}$ to homogenize the mixture. (ii)

Table 1 Chemical composition and physical characteristics of tested cement and MK

\begin{tabular}{|c|c|c|c|c|}
\hline \multirow[t]{2}{*}{ Measured property } & CEM I $42.5 \mathrm{~N}$ & MK & SF & FA \\
\hline & \multicolumn{4}{|c|}{ Oxide compositions/\% (by mass) } \\
\hline $\mathrm{SiO}_{2}$ & 19.84 & $52-53$ & 96.43 & 54.4 \\
\hline $\mathrm{Al}_{2} \mathrm{O}_{3}$ & 5.38 & $43-44$ & 0 & 26.5 \\
\hline $\mathrm{Fe}_{2} \mathrm{O}_{3}$ & 3.22 & $<1$ & 0,073 & 4.8 \\
\hline $\mathrm{Ca} 0$ & 64.90 & $<0,5$ & 0,78 & 3.5 \\
\hline $\mathrm{Mg0}$ & 1.38 & $<0,4$ & 0,70 & 2.5 \\
\hline $\mathrm{SO}_{3}$ & 2.97 & - & 0,038 & 1.7 \\
\hline $\mathrm{K}_{2} \mathrm{O}$ & 0.78 & $<1$ & 1,28 & 0.6 \\
\hline $\mathrm{Cl}$ & 0.0048 & - & - & - \\
\hline $\mathrm{Na}_{2} \mathrm{O}$ & - & $<0,1$ & - & 0.4 \\
\hline $\mathrm{TiO}_{2}$ & - & $<1$ & - & 1.5 \\
\hline Loss on ignition/ $\%$ & 3.0 & 1.59 & 2.8 & 2.3 \\
\hline Density $/ \mathrm{g} \mathrm{cm}^{-3}$ & 3.13 & 2.6 & 2.2 & 2.15 \\
\hline $\begin{array}{l}\text { Specific surface area/ } \\
\mathrm{cm}+2 \mathrm{~g}^{-1}\end{array}$ & 4000 & 22,000 & 24,000 & 4800 \\
\hline
\end{tabular}




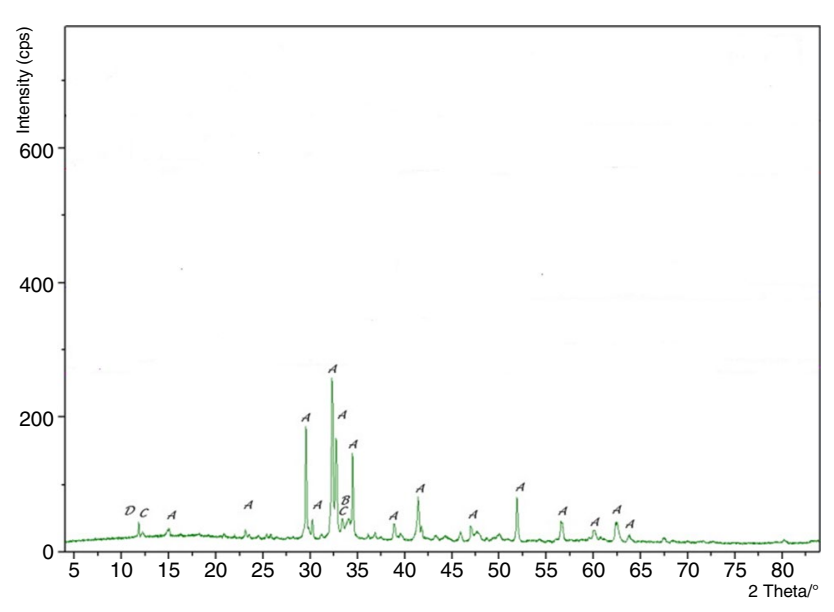

Fig. 1 The X-ray diffraction of cement

two minutes duration of mixing with water, to avoid the agglomeration of un-hydrated particles, which the total amount of water mixed with three-quarters of the total binder amount. Therefore, to achieve the highest homogeneity the remaining amount added during the mixing. MasterGlenium 300 superplasticizer the second generation has been used with a ratio of $0.2 \%$ to cement mass.

The paste was cast in prisms with a size of $40 \times 40 \times 160 \mathrm{~mm}$, then using vrating table for compaction. The casted samples were placed for $24 \mathrm{~h}$ in the lab conditions $\left(20 \pm 2{ }^{\circ} \mathrm{C}\right.$ and approximately $35 \%$ of relative humidity) until de-molding. Thereafter, they cured for 7 days in the water tank, then the specimens were stored in the lab until reaching the age of testing.

\section{Heating and testing procedures}

In the evaluation of the flexural performance of HCP made by pozzolanic materials after being exposed to elevated temperatures, three materials were used SF, MK, and FA. In all 28 mixtures were prepared, in which the performance of the three pozzolans results in 16 mixtures have been produced by using constant $\mathrm{w} / \mathrm{b}$ ratio $(0.3)$. Three groups based on the type of SCM, each group divided into six mixtures of $\mathrm{HCP}$ with regular replacement i.e., $0 \%, 3 \%, 6 \%, 9 \%, 12 \%$, and $15 \%$ by cement mass (see Fig. 3). The mix design of one type of SCM with $0.3 \mathrm{w} / \mathrm{b}$ ratios is shown in Table 2. Where the finding of optimum replacement of SF, MK, or FA is very important for paste performance, otherwise, the application of over the optimum replacement may reduce the mechanical and durability properties. In this paper, only the flexural results as mechanical properties are presented.

The method of testing and heating program has been applied as the following:

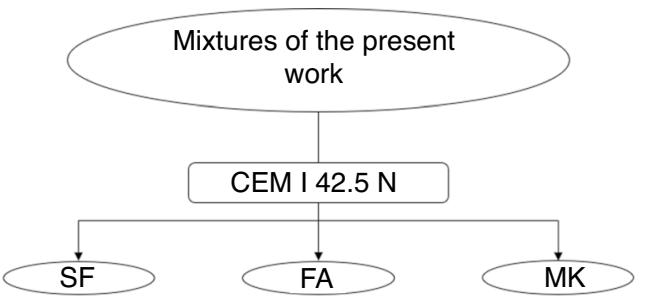

SCM replacements: $0 \%, 3 \%, 6 \%, 9 \%, 12 \%$, and $15 \%$ to cement mass

Fig. 3 General experimental program

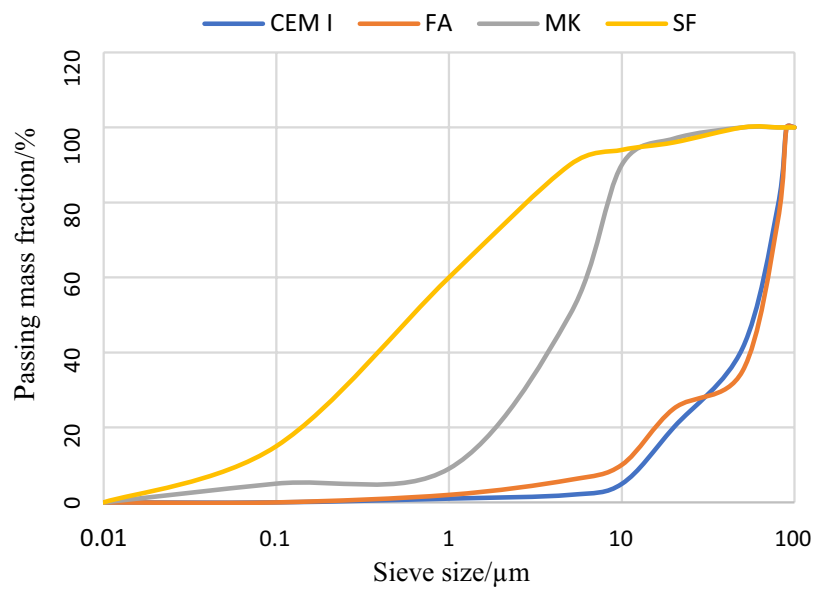

Fig. 2 Grading curves of cement

At the age of 90 days, the testing of specimens has been conducted which is recommended by RELIM for the taking place of the pozzolanic reaction in addition to reflect the real performance of the concrete in the fire. The heating program has been applied for every three prisms, by heating up to the target temperature for two hours. Different levels of temperatures were: $20,50,150,300,400,500,800$, and $900{ }^{\circ} \mathrm{C}$, then, the cooling down of specimens have been naturally and slowly in the lab air conditions $\left(20 \pm 2{ }^{\circ} \mathrm{C}\right.$ and approximately $35 \%$ of relative humidity) for a duration of $24 \mathrm{~h}$.

Table 2 Experimental matrix with varied ratios of SCM for $0.3 \mathrm{w} / \mathrm{b}$ ratio

\begin{tabular}{lll}
\hline Mixture proportion in $\mathrm{kg} \mathrm{m}^{-3}$ & & \\
\hline $\begin{array}{l}\text { SCM replacements to cement } \\
\text { mass/\% }\end{array}$ & CEM I & Water \\
\hline 0 & 480 & 144 \\
3 & 465.6 & 144 \\
6 & 451.2 & 144 \\
9 & 436.8 & 144 \\
12 & 422.4 & 144 \\
15 & 408 & 144 \\
\hline
\end{tabular}


The temperature range used in this experimental study is similar to the temperature range that could occur in the situation of real fire for $1 \mathrm{~h}$ [22]. An electrical furnace was used, see Fig. 4, the heating curve was set up similar to the ISO 834 standard fire curve for buildings up to $800{ }^{\circ} \mathrm{C}$, where the heating curve was just the same as the standard fire ISO 834 heating curve EN 1991-1-2:2002 [23].

The number of specimens tested for each strength value is three, where the average of the three values is reported. The number of prisms through the current experimental work is in the function of temperatures. In the presented work 672 prisms were tested.

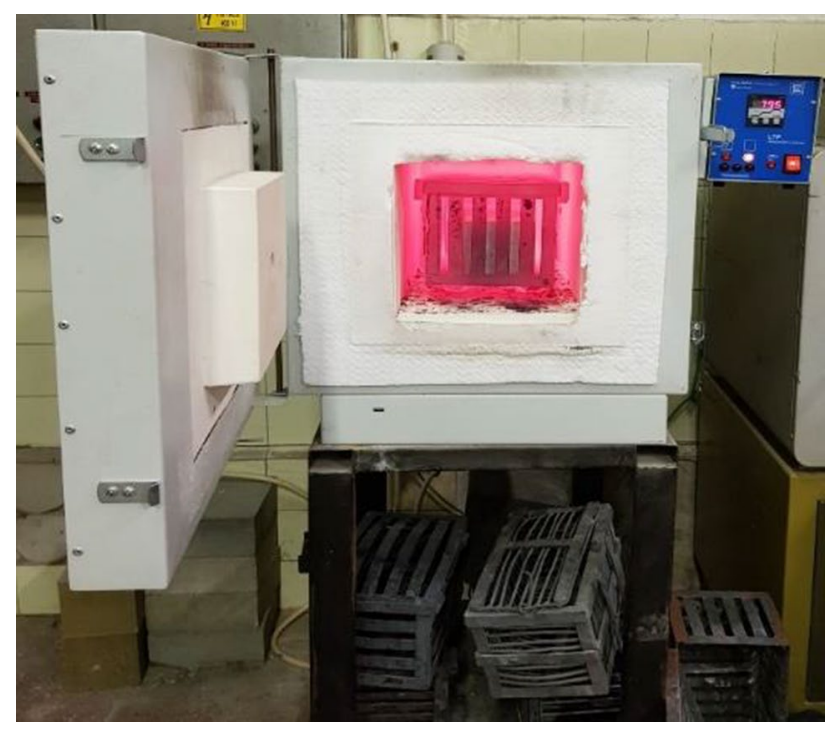

Fig. 4 Electrical furnace containing a steel cage

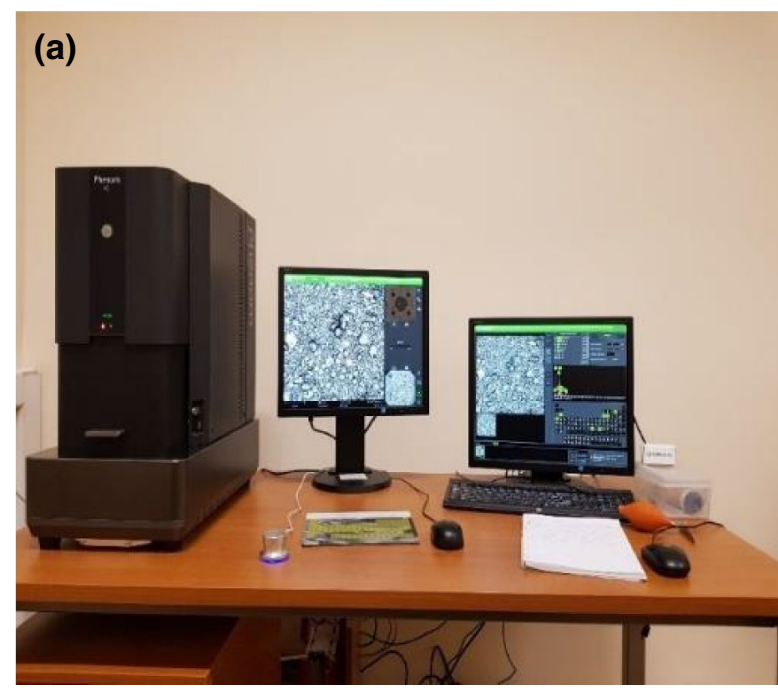

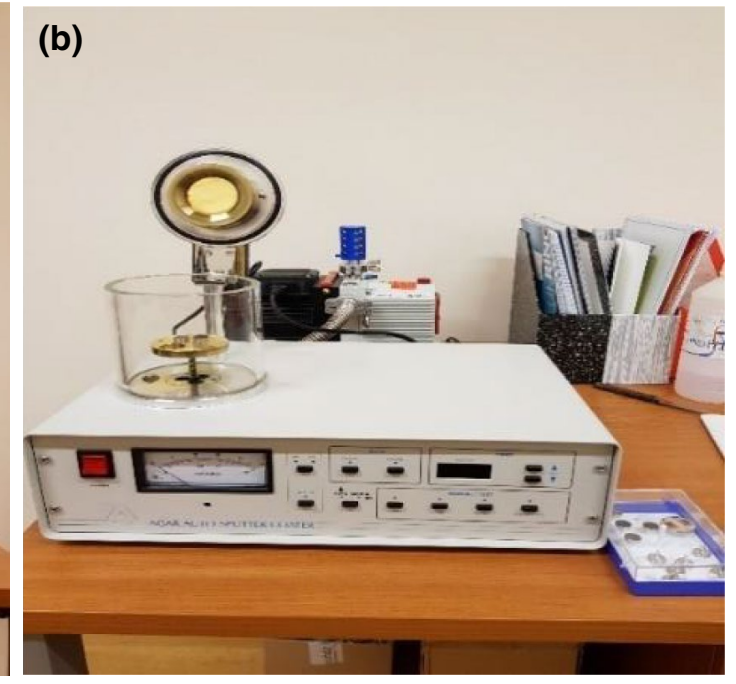

\section{Thermo-gravimetric measurements}

TG investigation defines the ranges of various thermal decompositions of HCP products in different temperatures levels with simultaneous estimation of the mass loss in static conditions. The different phases are controlled by TG/DTG/ DTA measurement, using MOM Derivatograph-Q 1500 D combined with software used for the estimation of the heat due to the dehydration of the chemical compounds. During the measurements, $\mathrm{Al}_{2} \mathrm{O}_{3}$ is the reference material and the mass of the sample is $300 \mathrm{mg}$. The heating rate of samples was $10^{\circ} \mathrm{C} \min ^{-1}$ up to $1000{ }^{\circ} \mathrm{C}$ in air atmosphere.

TG samples have been prepared to be a fine powder; the grounded powders have been selected from the core of specimens to ensure the soundness of samples from carbonation. The thermo-analytical test results are determined by Winder (Version 4.4.) software. The tested powders have been taken from specimens of ambient temperatures $20^{\circ} \mathrm{C}$. The investigated powders are for the optimum replacements of SCM after exposure to elevated temperatures. The TG/ DTA studies have been carried out when samples have an age of 90 days.

\section{Scanning electron-microscopic}

The chemical compound that affects the HCP performance and the changes in the microstructure due to the presence of pozzolans were investigated by SEM. After the flexural strength test, the core of the cross-section areas of the specimen was prepared and coated with gold for $30 \mathrm{~s} \mathrm{Fig.} \mathrm{5b,} \mathrm{then}$ observed under Phenom XL SEM Fig. 5a. However, it is important to get enough information about the evolution of the microstructure due to pozzolanic materials.

Fig. 5 Phenom XL desktop SEM: (a) SEM, and (b) vacuum chamber

Fig. 5 Phenom XL desktop SEM. (a) SEM, and (b) vacuum chamber 

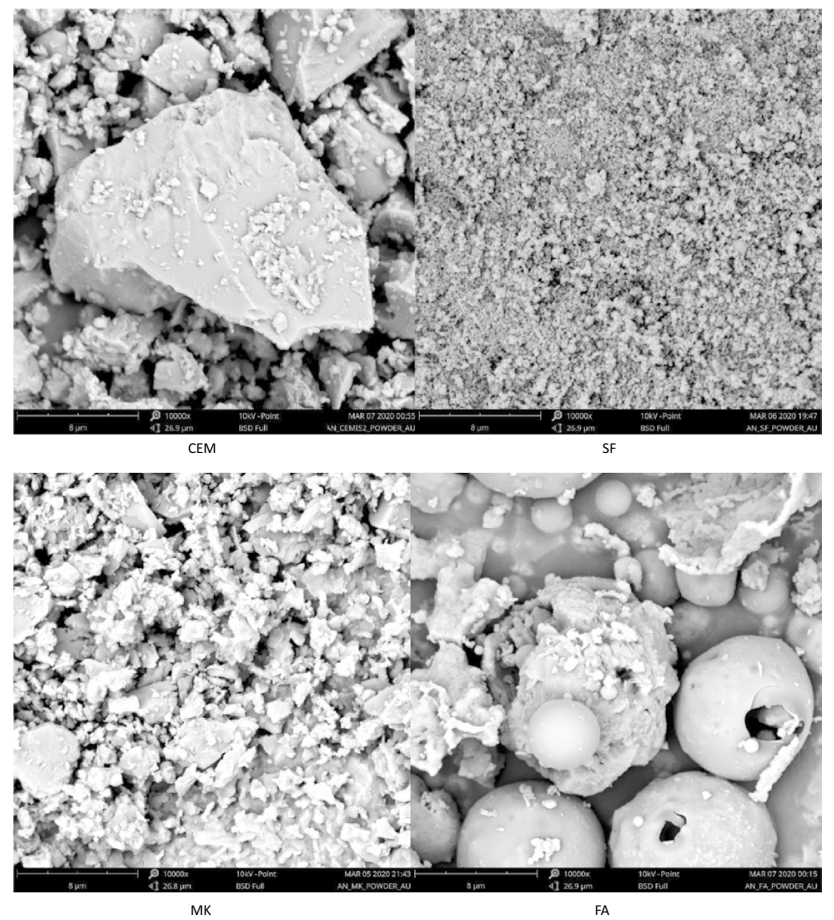

Fig. 6 SEM images of particles powders

\section{Computed Tomography measurement}

Slice image or tomography is a Greek-originated word. Tomographic images are obtained from a large series of two-dimensional X-ray images were taken in a different direction. In addition, these cross-sectional images can be combined into a three-dimensional image of the specimens inside the structure. Computed Tomography (CT) images were produced for the samples to investigate the distribution and the volume of pores in HCP made by pozzolanic material. The tested sample by $\mathrm{CT}$ was conducted only on SF specimens. The CT tests were carried out by a Siemens Somatom 16 device at the Diagnostic and Oncoradiology Institute of Kaposvar University in Hungary.

\section{Results and discussions}

\section{Powder morphology}

Typical SEM images of cement, SF, MK, and FA have presented in Fig. 6. Cement particles have an irregular polygonal shape. Where the particle sizes range from 15 to less than $0.5 \mu \mathrm{m}$. SF particles are very small and contact with each other. FA generally consists of hollow glassy spheres with various sizes as shown in Fig. 6. MK particles are elongated like microfibers and some particles like flakes with a rough surface. The used SF, MK, and FA are much finer than the used ordinary cement. Where the characteristics of the used powder promise to enhance the properties of HCP after elevated temperatures exposure.

\section{Results of the flexural test before exposure to elevated temperatures}

The flexural strength results of HCP incorporated by SF, FA, and MK with different SF replacements for $0.3 \mathrm{w} / \mathrm{b}$ ratios are presented in Fig. 7. The flexural strength values for all mixtures are varied between 2 to $11 \mathrm{MPa}$. Results showed that the presence of SF and FA relatively enhances the flexural results of HCP compared to the results of the reference mixture. Pozzolanic materials are fine materials, they enhance the flexural strengths of HCP by two fundamental mechanisms. The first mechanism is the filling of interstitial pores inside the skeleton mesh of HCP, thereby improving its density and strength as well. The second contribution is the pozzolanic reaction with the free $\mathrm{Ca}(\mathrm{OH})_{2}$ liberated during cement hydration, resulting in additional strength. The reduction in the flexural strengths at high replacements is attributed to the decrease of $C_{3} S$ and $\beta-C_{2} S$ phases in OPC due to the dilution effect by pozzolans [24]. On the other hand, MK incorporation decreases the flexural strength, this could be attributed to the low $\mathrm{w} / \mathrm{b}$ ratio used in addition to the high absorption capacity of MK particles provided by the surface roughness.

It is worth to mention that the compressive strength results of the mixtures are high strength values, but they are not presenting herein.

\section{Relative residual bending strength}

The bending strength of HCP has been tested at ambient temperature at the age of 90 days which recommended by RILEM for the paste due to the development of the pozzolanic reaction [25].

The relative residual flexural strength results (RRFS) of the three SCM with different replacements as a function of temperature are presented in this section. RRFS is defined by division of the residual flexural strength after each temperature level by the flexural strength of the same mixture at $20^{\circ} \mathrm{C}$. Due to the complexity of curves, the authors support the results by expressing the results of the area under each curve of RRFS (Fig. 11) [26].

\section{Performance of pozzolanic material}

Using any of the three SCM improves the heat endurance ability of HCP, by elevating the temperatures, the flexural strength is relatively enhanced due to three main actions i.e., hydration of un-hydrated SCM particles with temperatures increase, the packing contribution, and the pozzolanic 
Fig. 7 Flexural strength results of all of SF, FA, and MK replacements at ambient temperatures/MPa for $0.3 \mathrm{w} / \mathrm{b}$

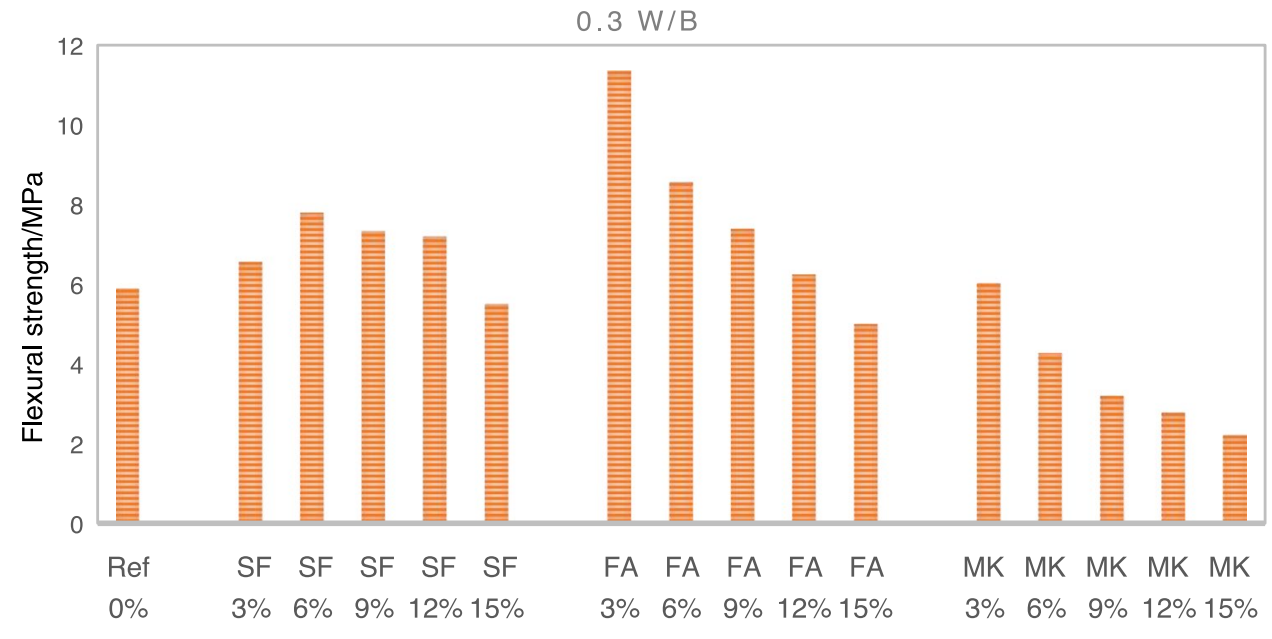

SCM type with different replacements replacements

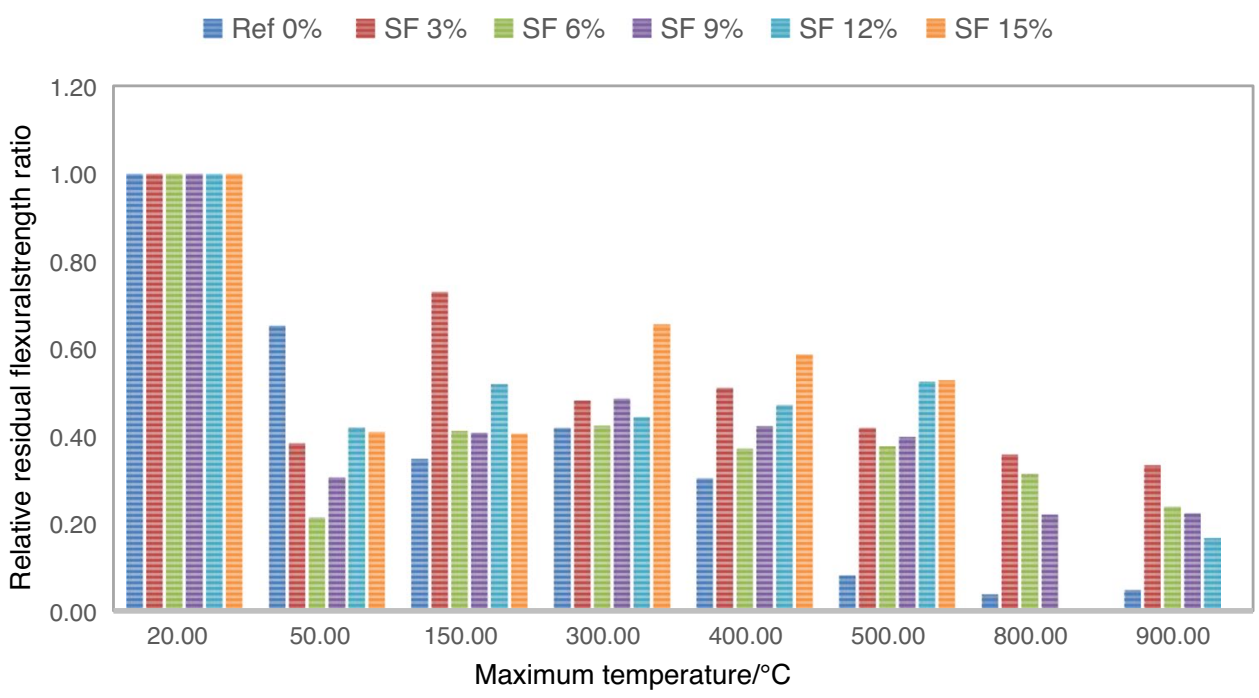

Fig. 8 RRFS of different replacements of SF after exposure to elevated temperatures and $53 \%$ for mixtures $0 \%, 3 \%, 6 \%, 9 \%, 12 \%$, and $15 \%$ of SF contents, respectively. However, the increase in the RRFS could be due to the activating of hydration, which works as heat curing. Also, the physical filler of SF, which contributes as fiber to the paste structure. Furthermore, the increase of temperatures to $900{ }^{\circ} \mathrm{C}$ the RRFS values are decreased due to the dense microstructure and formation of microcracks in case of high replacements of SF. Consequently, the spalling took place for the mixtures contain $12 \%$ and $15 \%$ of SF at $800{ }^{\circ} \mathrm{C}$ and for $15 \%$ replacement at $900{ }^{\circ} \mathrm{C}$ as well see Fig. 8. Moreover, the RRFS of other high replacements of SF marginally decreases at elevated temperatures to reach the maximum at the low replacement of $3 \%$ with $36 \%$ and $34 \%$ for $800{ }^{\circ} \mathrm{C}$ and $900{ }^{\circ} \mathrm{C}$, respectively. On the other hand, the reference mixture showed a significant loss after $400{ }^{\circ} \mathrm{C}$ exposure, the RRFS were reached $4 \%$ and $5 \%$ after exposure 
Fig. 9 RRFS of different replacements of MK after exposure to elevated temperatures
Fig. 10 RRFS of different replacements of FA after exposure to elevated temperatures
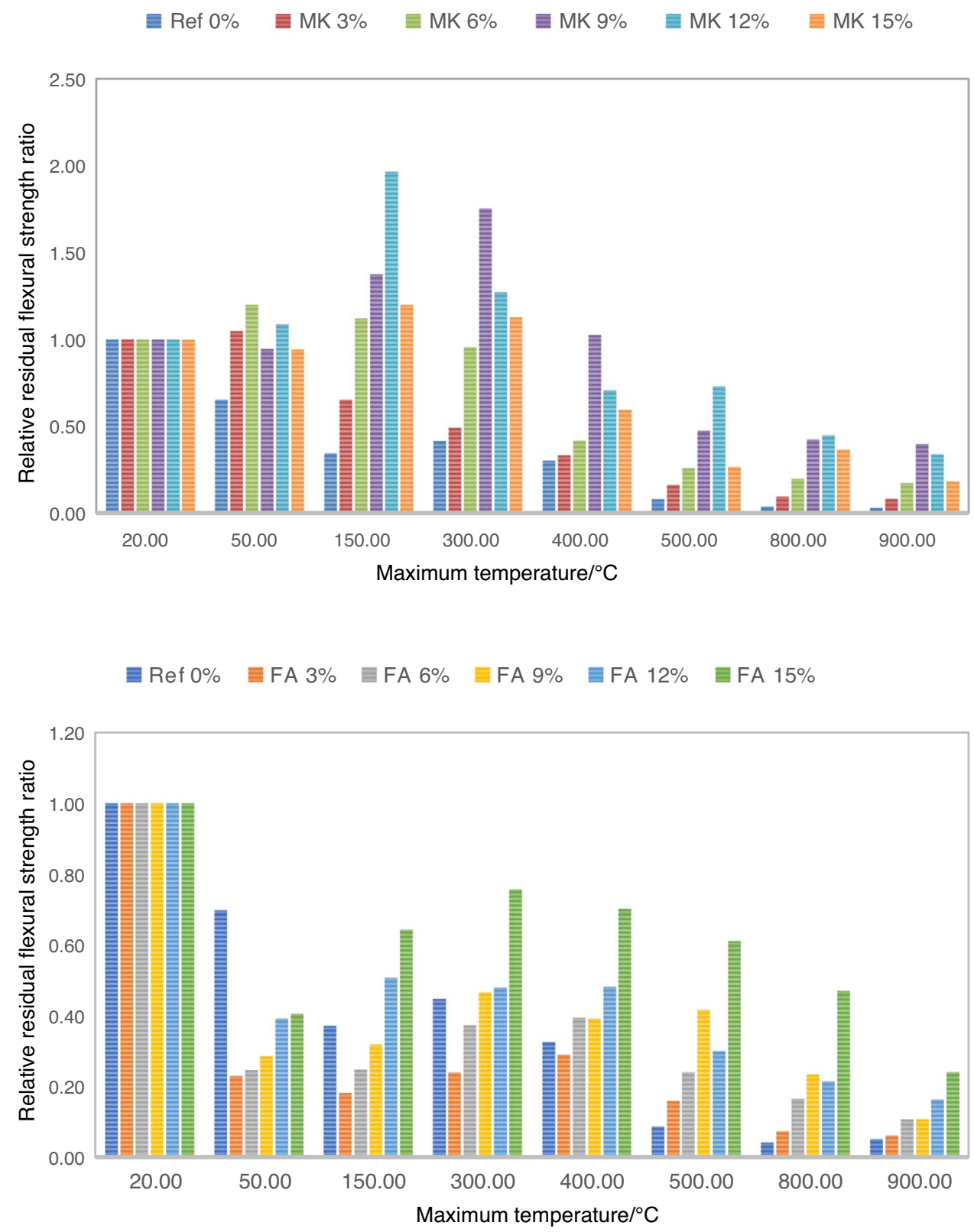

to $800{ }^{\circ} \mathrm{C}$ and $900{ }^{\circ} \mathrm{C}$, respectively. The decrease in RRFS is mainly due to two in sequence chemical reactions, from 450 to $550{ }^{\circ} \mathrm{C}$ corresponds to the dihydroxylation of $\mathrm{Ca}(\mathrm{OH})_{2}$, thereafter due to decomposition of $\mathrm{CaCO}_{3}$ [24].

Figure 9 shows the RRFS results of all mixtures of $\mathrm{MK}$ replacements. By the elevation of temperatures, the contribution of MK starts to appear by the activation provided by steam movement in the HCP matrix which works as curing. Mixture containing $12 \%$ of MK shows better performance than the other used replacements, showing the highest RRFS at 500 and $800{ }^{\circ} \mathrm{C}$ by $79 \%$ and $49 \%$, respectively. The chemical compositions and the morphology of the particle of MK enhance the properties of HCP after exposure to elevated temperatures.
The RRFS results of all FA mixtures are presented in Fig. 10. The results show the additional enhancement added to the HCP in the presence of FA. The RRFS proportionally increases as FA replacement increases, the chemical compositions of FA and the hollow particles' structures help the HCP to maintain high RRFS. The mixture containing $15 \%$ of FA shows the highest RRFS, achieving RRFS of $61 \%$ and $47 \%$ at 500 and $800{ }^{\circ} \mathrm{C}$, respectively.

Figure 11 shows the heat endurance of all mixtures for all of SF, MK, and FA. As shown in the figure the heat endurance increases in the presence of SCM. The adoption of $3 \%, 12 \%$, and $15 \%$ of the following SCM i.e., SF, MK, and FA, respectively, are significantly improved the heat endurance and could be considered as optimum replacements. 


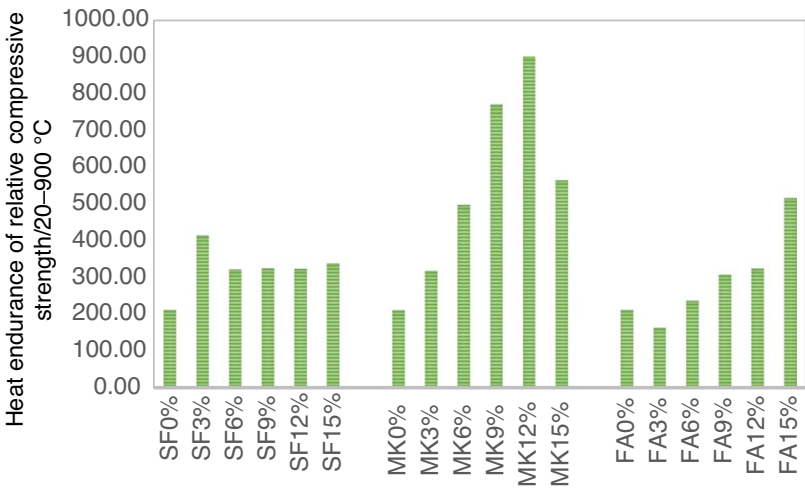

Fig. 11 Heat endurance of mixtures of SF, MK, and FA made by 0.3 $\mathrm{w} / \mathrm{b} / 20-900{ }^{\circ} \mathrm{C}$

Table 3 Optimum dosages of SF, MK, and FA

\begin{tabular}{llcc}
\hline \#Materials & $\mathrm{SF} / \%$ & $\mathrm{MK} / \%$ & $\mathrm{FA} / \%$ \\
\hline Ambient temperatures & 6 & 3 & 3 \\
Elevated temperatures & 3 & 12 & 15 \\
\hline
\end{tabular}

The optimum replacement of MK has shown a better heat endurance than the optimum replacements of SF and FA, this could be due to the morphological properties and chemical compositions of MK such as angular shapes of particles and high content of $\mathrm{Al}_{2} \mathrm{O}_{3}$ and $\mathrm{SiO}_{2}$.

Table 3 summarizes the optimum replacements of the used SF, MK, and FA at ambient and after exposure to elevated temperatures. The optimum replacements obtained at ambient temperatures are not similar to the optimum replacement after exposure to elevated temperatures. The properties of HCP before and after exposure to elevated temperatures are affected by many factors with different degrees such as the ratio of $\mathrm{w} / \mathrm{b}, \mathrm{Ca}(\mathrm{OH})_{2}$ content, $\mathrm{CaCO}_{3}$ content, and replacement amount of SCM.

\section{Thermo-gravimetric results}

The DTA/TG test carried out on HCP samples with SF, FA, and MK are shown in Fig. 12. Thermo-analytical results have shown four endothermic peaks. The first peak observed at $20-200{ }^{\circ} \mathrm{C}$, is mainly due to the driving out of total physical combined water, and dehydration of ettringite and monosulfate. The second peak was observed at $430-540{ }^{\circ} \mathrm{C}$ is due to dissociation of $\mathrm{Ca}(\mathrm{OH})_{2}$ content. The third peak at $600-740{ }^{\circ} \mathrm{C}$ can be the indicator for the dehydration of $\mathrm{CaCO}_{3}$ content. Finely the fourth peak at 740-900 ${ }^{\circ} \mathrm{C}$ may indicate the second peak for $\mathrm{CSH}$ decomposition [28-30].

Incorporation of any of SF, FA, or MK increases the mass loss due to evaporation of total physical combined this

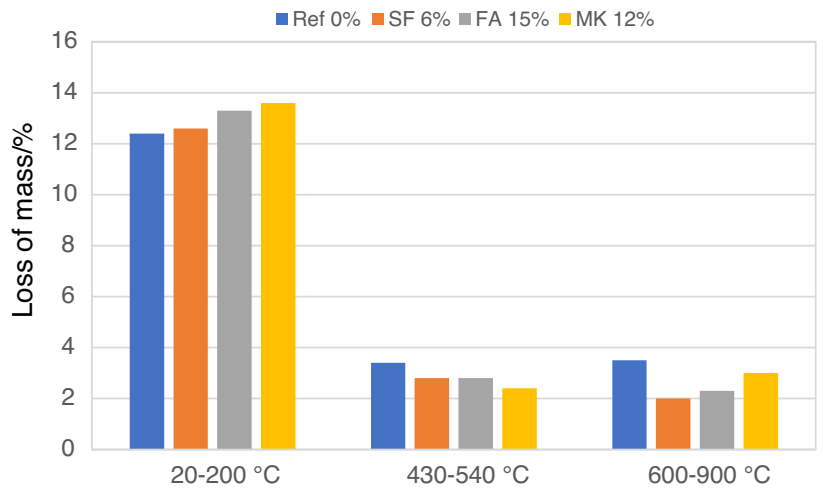

Fig. 12 Loss of mass of different phases using TG/DTA

performance could be related to the high absorption capacity of these SCM. Less loss of mass was observed by the inclusion of SF, FA, or MK corresponds to the second peak, in which $\mathrm{SCM}$ decreases the $\mathrm{Ca}(\mathrm{OH})_{2}$ content and producing additional strength. Finally, the last peak indicates that SF, FA, or MK decreases the loss of mass due to the $\mathrm{CaCO}_{3}$ decomposition [30].

Generally, the effects of pozzolans on heat endurance of $\mathrm{HCP}$ properties are significant due to the pozzolanic activity which based on the consumption of $\mathrm{Ca}(\mathrm{OH})_{2}$.

\section{Scanning electron microscopy analysis}

SEM images for blended HCP at ambient and after exposure to $500{ }^{\circ} \mathrm{C}$ are presented in Fig. 13. For the reference mixture, high content of $\mathrm{Ca}(\mathrm{OH})_{2}$ crystals and a porous composite mass of CSH and mono-sulfate are observed. After $500{ }^{\circ} \mathrm{C}$, the microstructure becomes more porous in addition to the formation of cracks due to the decomposition of $\mathrm{Ca}(\mathrm{OH})_{2}$ and ettringite. Resulting in deterioration of HCP microstructure which was confirmed by the flexural properties test. The presence of SF, MK, or FA decreases the content of $\mathrm{Ca}(\mathrm{OH})_{2}$ and producing a very dense structure of $\mathrm{CSH}$ in the form of a honeycomb structure. Thereafter, the microstructure becomes refractory against elevated temperature. Finally, the cracks were discontinuing due to the filling effect provided by SCM [31-33].

\section{CT results}

As an attempt to evaluate the effect of SCM replacement on the density development of HCP, the CT Investigation was only used for SF. The CT images were captured for specimens' size of $\varnothing 100 \times 50 \mathrm{~mm}$ through a very thin-slicing in the whole cross-section. Figure 14 shows the porosity of the produced HCP. The results showed that the amount of the pores decreased with the addition of SF, the porosity was $5.93 \%$ in 
Fig. 13 The SEM pictures of microstructures of reference and blended HCP mixtures at 20 and $500{ }^{\circ} \mathrm{C}$

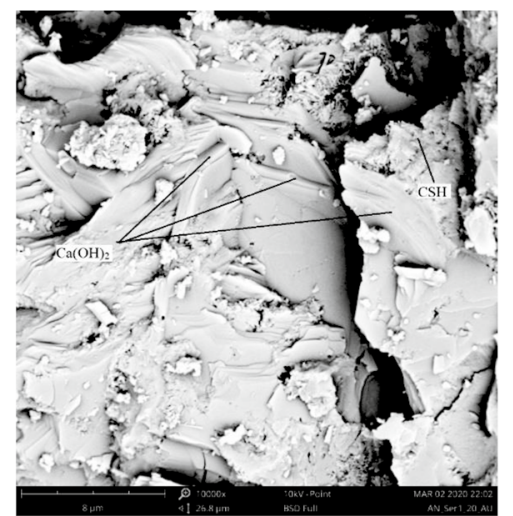

Reference $\mathrm{HCP}$ at $20^{\circ} \mathrm{C}$

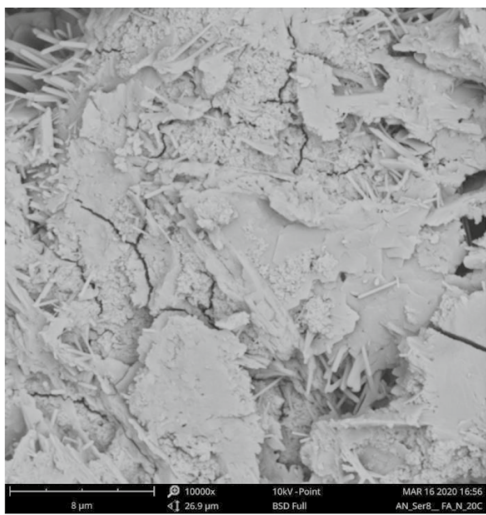

$\mathrm{HCP}$ containing $\mathrm{SF}$ at $20^{\circ} \mathrm{C}$

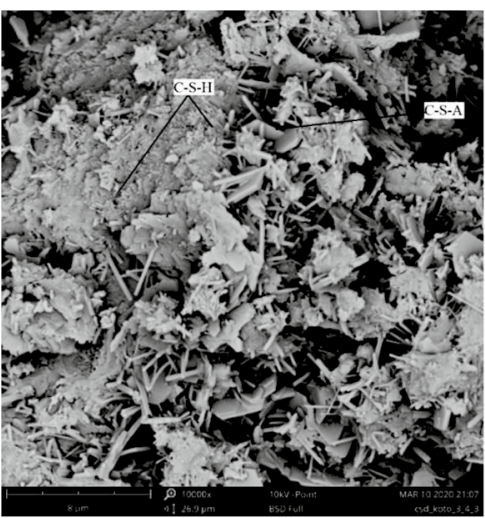

$\mathrm{HCP}$ containing MK at $20^{\circ} \mathrm{C}$

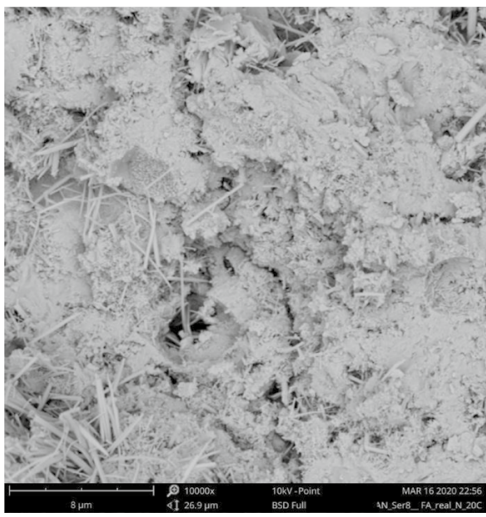

$\mathrm{HCP}$ containing FA $20^{\circ} \mathrm{C}$

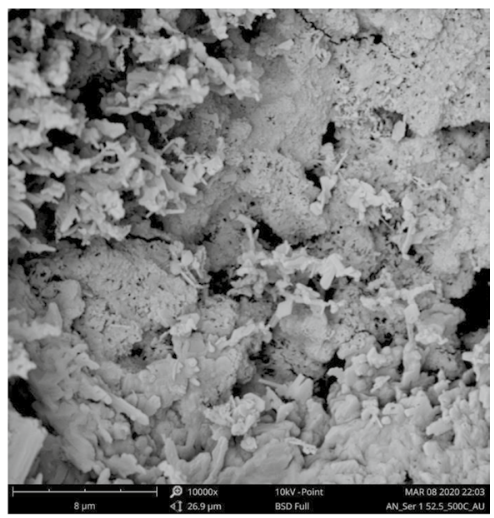

Reference $\mathrm{HCP}$ at $500^{\circ} \mathrm{C}$

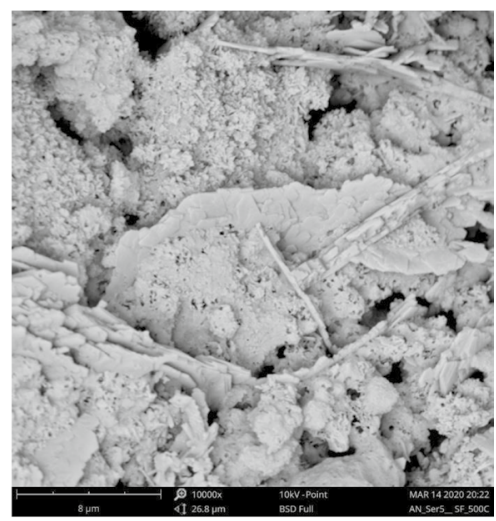

$\mathrm{HCP}$ containing SF at $500^{\circ} \mathrm{C}$

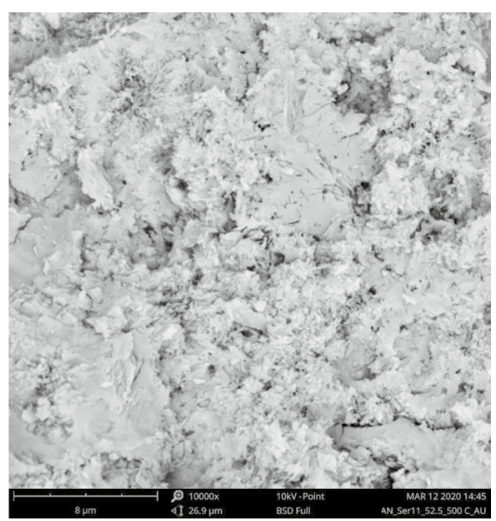

$\mathrm{HCP}$ containing $\mathrm{MK}$ at $500^{\circ} \mathrm{C}$

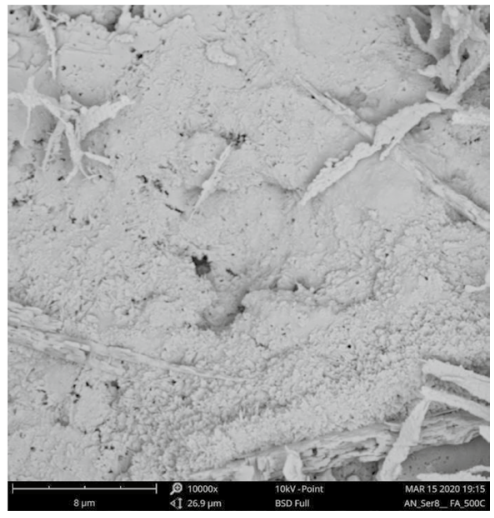

HCP containing FA $500{ }^{\circ} \mathrm{C}$ 
Fig. 14 Pores volume results of the reference HCP mixture and a mixture containing $6 \%$ of SF

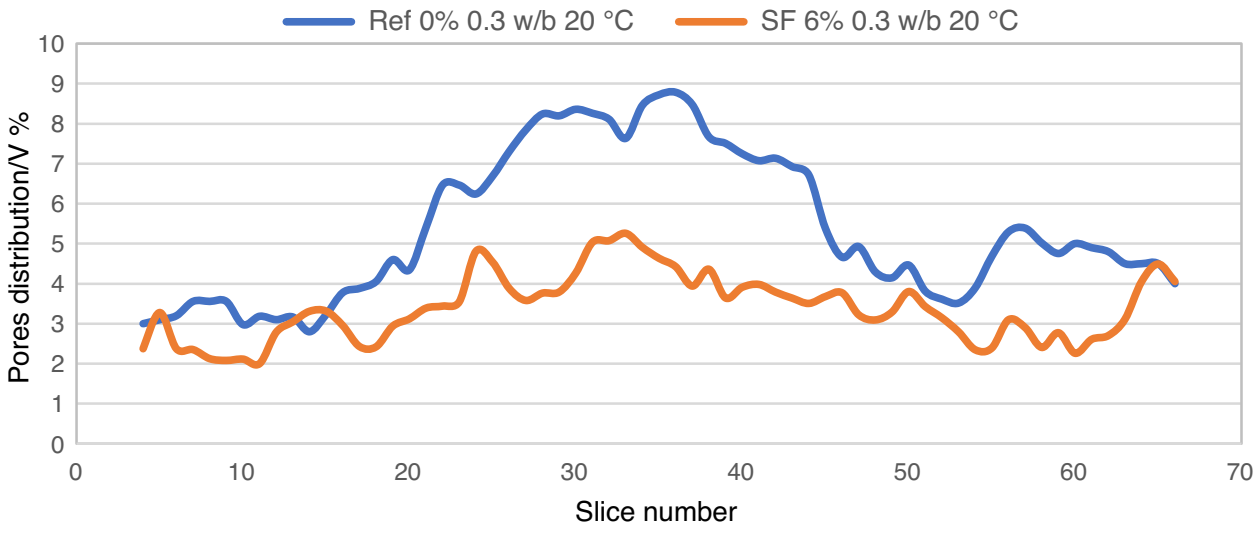

the reference HCP. On the other hand, the inclusion of $6 \%$ of SF decreased the porosity to $3.53 \%$ (Fig. 14). The decrease of the porosity is one of the reasons for the positive contribution of SCM in HCP after exposure to elevated temperatures. However, producing high dense HCP could adversely affect the properties of HCP, this outcome is very clear at high SF replacements (12\% and $15 \%)$ where the spalling took place.

\section{Conclusions}

In this paper, the flexural performance of different pozzolanic materials (SF, MK, and FA) hardened pastes subjected to different temperatures levels between 20 and $900{ }^{\circ} \mathrm{C}$ has been investigated. The effect of SF, MK, or FA with short incremental replacement in the flexural behaviour is not covered in the literature in addition to the comparison between the three pozzolan's performance from the perspective of heat endurance. The conclusions drawn from the results are as follows:

- Mixtures without pozzolans showed a very weak capacity after exposure to elevated temperatures, in which the RRFS values were $8 \%$ and $4 \%$ at 500 and $800{ }^{\circ} \mathrm{C}$, respectively.

- Incorporation of SF has improved the RRFS after exposure to elevated temperatures. Adoption of 3\% of SF has shown the highest RRFS to reach $42 \%$ and $36 \%$ values at 500 and $800{ }^{\circ} \mathrm{C}$, respectively.

- Using $12 \%$ of MK strongly enhances the RRFS after exposure to elevated temperatures. The RRFS has been $79 \%$ and $49 \%$ at 500 and $800{ }^{\circ} \mathrm{C}$, respectively.

- The results of FA have shown a great contribution to the RRFS of HCP after exposure to elevated temperatures, replacing cement by $15 \%$ of FA has shown the highest RRFS to reach $61 \%$ and $47 \%$ at 500 and $800{ }^{\circ} \mathrm{C}$, respectively.

- Comparison of flexural results between SF, MK, and FA after the exposure to elevated temperature was conducted and supported by the heat endurance calculations. The obtained results have shown that MK maintained the highest heat endurance.
- CT results confirmed that SF significantly densifies the $\mathrm{HCP}$.

- The enhancement in the heat endurance takes its root from the microstructure alteration occurred in the presence of the used SCM such as decreasing the content of $\mathrm{Ca}(\mathrm{OH})_{2}$ and $\mathrm{CaCO}_{3}$, increasing the content of $\mathrm{CSH}$ and $\mathrm{CASH}$, and decreasing the porosity.

- Knowing the physical morphology of the cementitious materials helps to evaluate the performance of concrete or $\mathrm{HCP}$ before and after exposure to elevated temperatures.

- Spalling has occurred at high replacements of SF (mixtures of $12 \%$ and $15 \%$ of SF) at $800{ }^{\circ} \mathrm{C}$. Results are supported by $\mathrm{CT}$ measurements, the porosity decreases in the presence of $6 \%$ of SF by about $2.4 \%$ from the total porosity content of the reference mixture. Therefore, using high SF replacements to cement with $\mathrm{w} / \mathrm{b}$ ratio of 0.3 is not recommended.

\section{Recommendations}

Using any of the used SCM particularly MK, and FA due to the high replacement obtained for the optimum replacement is recommended for the production of sustainable and environmentally friend concrete. Encouraging researchers to introduce any other new types of SCM to the field of construction material would be preferable.

Providing heat resistance and durable HCP could be recommended for use with any type of aggregate.

The property of concrete/HCP under flexural load is not similar to under compression load especially after exposure to elevated temperatures, due to the fact, the flexural property is very sensitive to cracks more than compression property.

Acknowledgements This research was carried out with the support of the Bolyai János Scholarships. The research was also supported by the Higher Education Institutional Excellence Program, under the topic program of the BME FIKP-WATER, announced by the Ministry of Human Resources. Supported by the ÚNKP-19-4 New National Excellence program of the Ministry for Innovation and Technology. Authors acknowledge the support by the Hungarian Research Grant 
NVKP_16-1-0019 "Development of concrete products with improved resistance to chemical corrosion, fire or freeze-thaw".

Funding Open access funding provided by Budapest University of Technology and Economics.

Open Access This article is licensed under a Creative Commons Attribution 4.0 International License, which permits use, sharing, adaptation, distribution and reproduction in any medium or format, as long as you give appropriate credit to the original author(s) and the source, provide a link to the Creative Commons licence, and indicate if changes were made. The images or other third party material in this article are included in the article's Creative Commons licence, unless indicated otherwise in a credit line to the material. If material is not included in the article's Creative Commons licence and your intended use is not permitted by statutory regulation or exceeds the permitted use, you will need to obtain permission directly from the copyright holder. To view a copy of this licence, visit http://creativecommons.org/licenses/by/4.0/.

\section{References}

1. Bažant ZP, Kaplan MF, Bazant ZP. Concrete at high temperatures: material properties and mathematical models. In: Kong, FK, editor. Longman group limited, London, England; 1996; pp. 1-410.

2. Akçaözoğlu K, Fener M, Akçaözoğlu S, Öcal R. Microstructural examination of the effect of elevated temperature on the concrete containing clinoptilolite. Constr Build Mater. 2014;72:316-25.

3. Peng GF, Huang ZS. Change in microstructure of hardened cement paste subjected to elevated temperatures. Construct Build Mater. 2008;22(4):593-9.

4. Mehta PK, Monteiro PJM. Concrete: structure, properties and materials. Englewood Cliffs: Prentice-Hall; 1993.

5. Lin WM, Lin TD, Powers-Couche LJ. Microstructures of firedamaged concrete. Mater J. 1996;93(3):199-205.

6. Rostasy FS, Wei $\beta$ R, Wiedemann G. Changes of pore structure of cement mortars due to temperature. Cem Concr Res. 1980;10(2):157-64.

7. Dettling H. The thermal expansion of hardened cement paste, aggregates and concrete (in german). Deutscher Ausschuss fur Stahlbeton. Bulletin No. 164, W. Ernst and Sohn, Berlin; 1964. pp 1-64 (translation No. 458, PCA Technical Information Department, Chicago).

8. Hertz KD. Concrete strength for fire safety design. Magaz Concr Res. 2005;57(8):445-53.

9. Karim MR, Chowdhury FI, Zabed H, Saidur MR. Effect of elevated temperatures on compressive strength and microstructure of cement paste containing palm oil clinker powder. Constr Build Mater. 2018;183:376-83.

10. Neves IC, Branco FA, Valente JC. Effects of formwork fires in bridge construction. Concr International. 1997;19(3):41-6.

11. Al-Mutairi NM, Al-Shaleh MS. Assessment of fire-damaged Kuwaiti structures. J mater Civ Engin. 1997;9(1):7-14.

12. Chan YN, Peng GF, Anson M. Residual strength and pore structure of high-strength concrete and normal strength concrete after exposure to high temperatures. Cem Concr Compo. 1999;21(1):23-7.

13. Hertz KD. Heat-induced explosion of dense concretes, Report No. 166, Institute of Building Design, Technical University of Denmark, Lyngby; 1984.

14. Sarshar R, Khoury GA. Material and environmental factors influencing the compressive strength of unsealed cement paste and concrete at high temperatures. Mag Concr Res. 1993;45(162):51-61.

15. Poon CS, Azhar S, Anson M, Wong YL. Performance of metakaolin concrete at elevated temperatures. Cem Concr Compos. $2003 ; 25(1): 83-9$.
16. Birchall JD, Howard AJ, Kendall K. Flexural strength and porosity of cements. Nature. 1981;289(5796):388-90.

17. Koksal F, Gencel O, Kaya M. Combined effect of silica fume and expanded vermiculite on properties of lightweight mortars at ambient and elevated temperatures. Constr Build Mater. 2015;88:175-87.

18. MSZ EN 196-2. Cement testing methods. Part 2: chemical analysis of cement. Budapest: Magyar Szabvanyugyi Testulet; 2013. (in Hungarian).

19. MSZ EN 525-12. Chemical analysis of cement. Part 12: determination of free lime content. Budapest: Magyar Szabvanyugyi Testulet; 2014. (in Hungarian).

20. EN 197-1. Cement - Part 1: Composition, specifications and conformity criteria for common cements; 2000.

21. EN 1008. Mixing water for concrete-Specification for sampling, testing and assessing the suitability of water, including water recovered from processes in the concrete industry, as mixing water for concrete; 2002.

22. Hlavička ÉLV. Bond after fire. Constr Build Mater. 2017;132:210-8.

23. ISO, I. 834. Fire resistance tests-elements of building construction. Geneva: International Organization for Standardization; 1999.

24. Morsy MS, Al-Salloum YA, Abbas H, Alsayed SH. Behavior of blended cement mortars containing nano-metakaolin at elevated temperatures. Constr Build Mater. 2012;35:900-5.

25. RILEM Technical Committees 129-MHT. Test methods for mechanical properties of concrete at high temperatures, part 1: introduction, part 2: stress-strain relation, part 3: compressive strength for service and accident conditions. Mater Struct. 1995;28(181):410-4.

26. Fehérvári S, Nehme SG. Effect of Concrete Components on the Temperature Endurance of Tunnel Linings (Doctoral dissertation, $\mathrm{Ph}$. D. Thesis, Budapest University of Technology and Economics, Budapest). 2009.

27. Lublóy E, Kopecskó K, Balázs GL, Restás Á, Szilágyi IM. Improved fire resistance by using Portland-pozzolana or Portlandfly ash cements. J Therm Anal Calorim. 2017;129(2):925-36.

28. Balázs GL, Kopecskó K, Alimrani N, Abdelmelek N, Lublóy É. Fire Resistance of Concretes with Blended Cements. In High Tech Concrete: Where Technology and Engineering Meet. Springer, Cham. 2018; pp. 1420-27.

29. Bakhtiyari S, Allahverdi A, Rais-Ghasemi M, Zarrabi BA, Parhizkar T. Self-compacting concrete containing different powders at elevated temperatures-Mechanical properties and changes in the phase composition of the paste. Thermochim Acta. 2011;514(1-2):74-81.

30. Ming X, Cao M, Lv X, Yin H, Li L, Liu Z. Effects of high temperature and post-fire-curing on compressive strength and microstructure of calcium carbonate whisker-fly ash-cement system. Const Build Mater. 2020;244:118333.

31. Rehman SKU, Ibrahim Z, Memon SA, Javed MF, Khushnood RA. A sustainable graphene based cement composite. Sustainability. 2017;9(7):12-29.

32. Abdelmelek N, Lubloy E. Evaluation of the mechanical properties of high-strength cement paste at elevated temperatures using metakaolin. J Therm Anal Calorim. 2020. https://doi.org/10.1007/ s10973-020-09992-2.

33. Abdelmelek N, Lubloy E. The impact of metakaolin, silica fume and fly ash on the temperature resistance of high strength cement paste. J Therm Anal Calorim. 2021. https://doi.org/10.1007/ s10973-021-10700-x.

Publisher's Note Springer Nature remains neutral with regard to jurisdictional claims in published maps and institutional affiliations. 